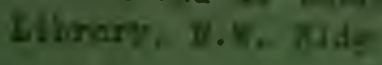

OCT 291963

NBS

Eechnical Note

no. 184

\title{
LUNAR OCCULTATIONS OF TWO DISCRETE RADIO SOURCES IN 1963-1964
}

JOHN A. EODY

U. S. DEPARTMENT OF COMMERCE NATIONAL BUREAU OF STANDARDS 


\section{THE NATIONAL BUREAU OF STANDARDS}

\section{Functions and Activities}

The functions of the National Bureau of Standards are set forth in the Act of Congress, March 3, 1901, as amended by Congress in Public Law 619, 1950. These include the development and maintenance of the national standards of measurement and the provision of means and methods for making measurements consistent with these standards; the determination of physical constants and properties of materials; the development of methods and instruments for testing materials, devices, and structures; advisory services to government agencics on scientific and technical problems; invention and development of devices to serve special needs of the Government; and the development of standard practices, codes, and specifications. The work includes basic and applied research, development, engineering, instrumentation, testing, evaluation, calibration services, and various consultation and information services. Research projects are also performed for other government agencies when the work relates to and supplements the basic program of the Bureau or when the Bureau's unique competence is required. The scope of activities is suggested by the listing of divisions and sections on the inside of the back cover.

\section{Publications}

The results of the Bureau's research are published either in the Bureau's own series of publications or in the journals of professional and scientific societies. The Bureau publishes three periodicals available from the Government Printing Office: The Journal of Research, published in four separate sections, presents complete scientific and technical papers; the Technical News Bulletin presents summary and preliminary reports on work in progress; and the Central Radio Propagation Laboratory Ionospheric Predictions provides data for determining the best frequencies to use for radio communications througliout the world. There are also five series of non periodical publications: Monographs, Applied Mathematics Series, Handbooks, Miscellaneous Publications, and Technical Notes.

A complete listing of the Bureau's publications can be found in National Bureau of Standards Circular 460, Publications of the National Bureau of Standards, 1901 to June 1947 (\$1.25), and the Supplement to National Bureau of Standards Circular 460, July 1947 to June 1957 $(\$ 1.50)$, and Miscellaneous Publication 240, July 1957 to June 1960 (includes Titles of Papers Published in Outside Journals 1950 to 1959) (\$2.25); available from the Superintendent of Documents, Government Printing Office, Washington 25, D.C. 


\title{
NATIONAL BUREAU OF STANDARDS Eechnical Mote 184 Issued October 11, 1963
}

\section{LUNAR OCCULTATIONS OF TWO DISCRETE RADIO SOURCES IN 1963-1964}

\author{
John A. Eddy \\ Central Radio Propagation Laboratory \\ National Bureau of Standards \\ Boulder, Colorado
}

NBS Technical Notes are designed to supplement the Bureau's regular publications program. They provide a means for making available scientific data that are of transient or limited interest. Technical Notes may be listed or referred to in the open literature.

For sale by the Superintendent of Documents, U. S. Government Printing Office

Washington, D.C. 20402

PRICE 20 CENTS 


\section{IMPORTANT NOTICE}

NATIONAL BUREAU OF STANDARDS REPORTS are usually preliminary or progress accounting documents intended for use within the Government. Before material in the reparts is farmally published it is subjected to additionol evaluation and review. Far this reasan, the publication, reprinting, repraduction, or apen-literature listing of this Report, either in whole or in part, is not authorized unless permission is obtained in writing from the Office of the Director, Notionol Bureau of Standords, Woshington 25, D. C. Such permission is nat needed, however, by the Government ogency for which the Report hos been specifically prepared if that ogency wishes to reproduce additional capies for its own use. 


\section{TABLE OF CONTENTS}

I. Introduction ................... I

II. Importance of Lunar Occultations .............. I

III. Occultations of Taurus A and IC443 in 1963-1964 ..... . 5

IV. Sumary ...................... 12

V. References .................. 15 


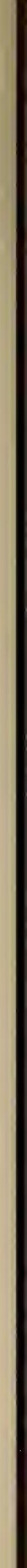


The bright, extended radio sources Taurus $A$. and IC443 lie close to the ecliptic and are occulted by the moon about every $8 \frac{1}{2}$ years, providing rare opportunities to study their angular brightness distribution with very high resolution. The nature of the next series of occultations of these sources, which will occur for observers at Boulder during the period from November 1963 through August 1964, is discussed.

\section{INTRODUCTION}

Eight years ago Bakulin and Shklovski [1955] published a reminder to radio astronomers that lunar occultations of two major radio sources were due to occur at different times over the earth in the year to come. The sources were Taurus A (Crab Nebula) and IC443, a galactic nebula in Gemini; they are the only extended radio sources of significant flux density that lie near the ecliptic. The period of recurrence of these events, fixed by the ecliptic latitude of the source, is eight to nine years. The last series were observed in Europe and Australia in October and November 1955 and in January 1956. They will recur in North America throughout the period from winter 1963 through summer 1964.

II. IMPORTANTE OF LUNAR OCCULTATIONS

There are three principal reasons for observing the lunar occultation of radio sources. First, an estimate of the electron density of the lunar atmosphere can be obtained from accurate comparison 
of the predicted times of occultation of radio source behind the moon [Link and Neuzil, 1954]. The presence of a lunar atmosphere will cause refraction of the radio waves received from the occulted source during the times of emersion and immersion and will thus cause the observed period of obscuration to be somewhat less than that expected in the absence of refraction. In this way Elsmore and Whitfield [1955] and Elsmore [1958] observed occultations of IC443 and Taurus A to derive an upper limit for the density of the lunar atmosphere of about $10^{-13}$ that of the atmosphere of the earth.

The second reason for observing a lunar occultation is to determine the precise position of the occulted source. From the known ephemerides of the moon, the time of occultation of a source can be translated directly into a very precise position of right ascension and declination. Since the accurate determination of the positions of radio sources is a major problem in the present techniques of radio astronomy, this method is of unique value. It is, of course, rather limited since only sources that lie within the path of the moon are available. Furthermore, most occultations give information on only the right ascension of the source; information on declination is afforded only in the case of a grazing occultation by the upper or lower limb of the lunar disk. Hazard [1961] has determined the right ascension of the source $3 \mathrm{C} 212$ to within 5 " of arc by this method and more recently [Bolton, 1963] has fixed the position of the distant source 3 C273 to within about $I^{\prime \prime}$.

Finally, occultations permit the study of the angular structure or brightness distribution of occulted sources with unusually high resolution. The method involved is precisely that employed in the study 
of solar eclipses: the disk of the moon acts as a screen that progressively isolates the emission from incremental areas of the source. For most sources observed at the higher frequencies in the radio case, the moon is a more intense emitter than the occulted source, but this does not exclude the method provided the emission from the occulted source is within the range of detection of the radio receiver. Resolution is limited only by the Fresnel diffraction pattern at the lunar limb and by the time and intensity resolution of the radiometer. Recently, Scheuer [1962] has shown that the Fresnel diffraction limitation (about 18 " of arc at $100 \mathrm{Mc} / \mathrm{s}$ and $6 "$ at $1000 \mathrm{Mc} / \mathrm{s}$ ) may be overcome by analytical reduction, so that the strip distribution of the occulted source may in practice be completely recovered from the diffraction records. The angular distribution of brightness across the Crab Nebula was studied by this method during the 1955-56 occultation by Costain, Elsmore, and Whitfield [1956]; Boischot, Blum, and LeRoux [1956]; Tuominen and Karras [1957]; and Seeger and Westerhout [1957]. The last occultation of IC443 was observed by Elsmore and Whitfield [1955] and by Rishbeth [1956], whose reconstruction of its angular distribution confirmed the tentative identification of the source that had been proposed by Baldwin and Dewhirst [1954]. Other sources whose angular distributions have been studied by lunar occultations are Kepler's Star [Rishbeth and Little, 1957; Talen, 1963], Jupiter, and 3C273 [Bolton, 1963]. The method again is limited to objects that lie near the ecliptic and whose flux densities are within the sensitivity range of the radiometer employed. It seems a particularly happy circumstance that the rather strong and interesting sources Taurus A and IC443 are included in these conditions. 


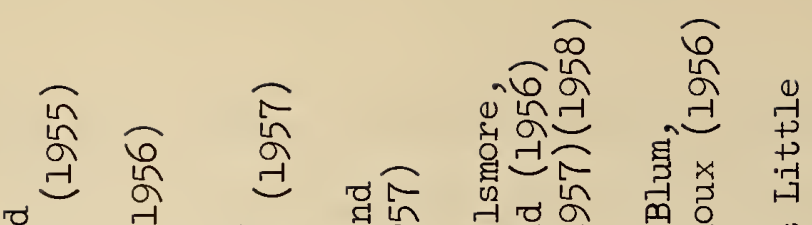

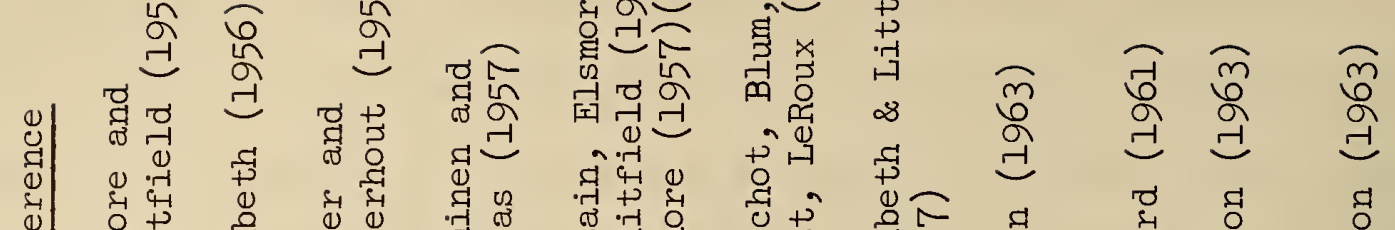

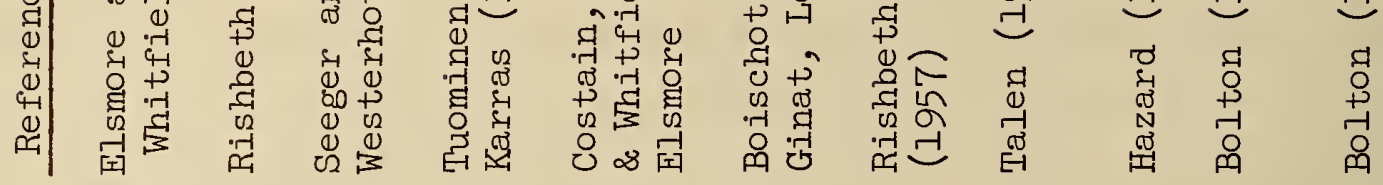

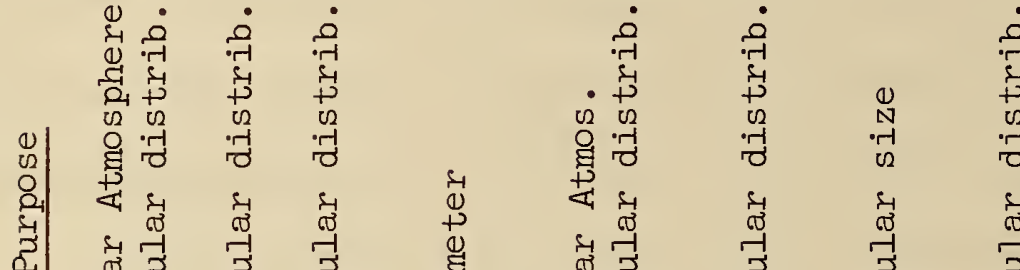

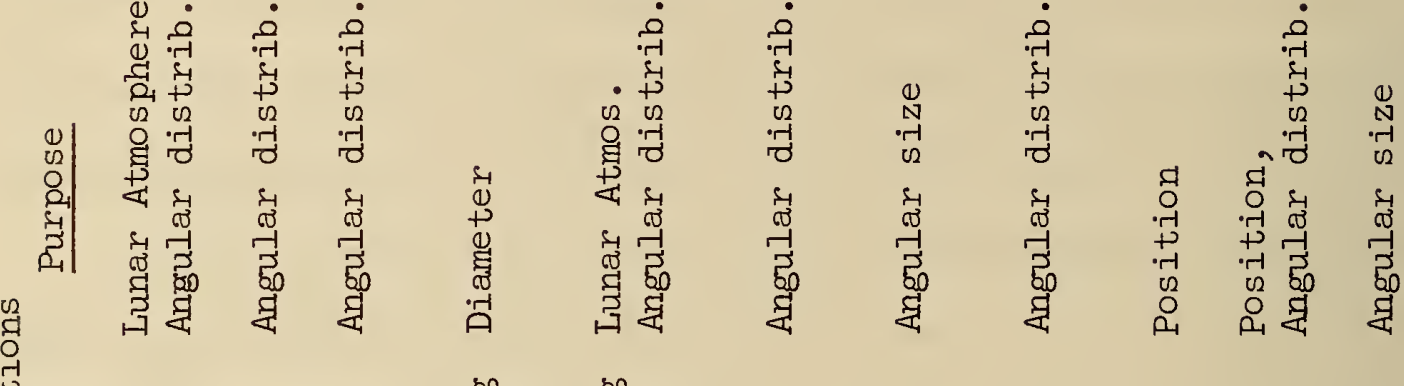

国

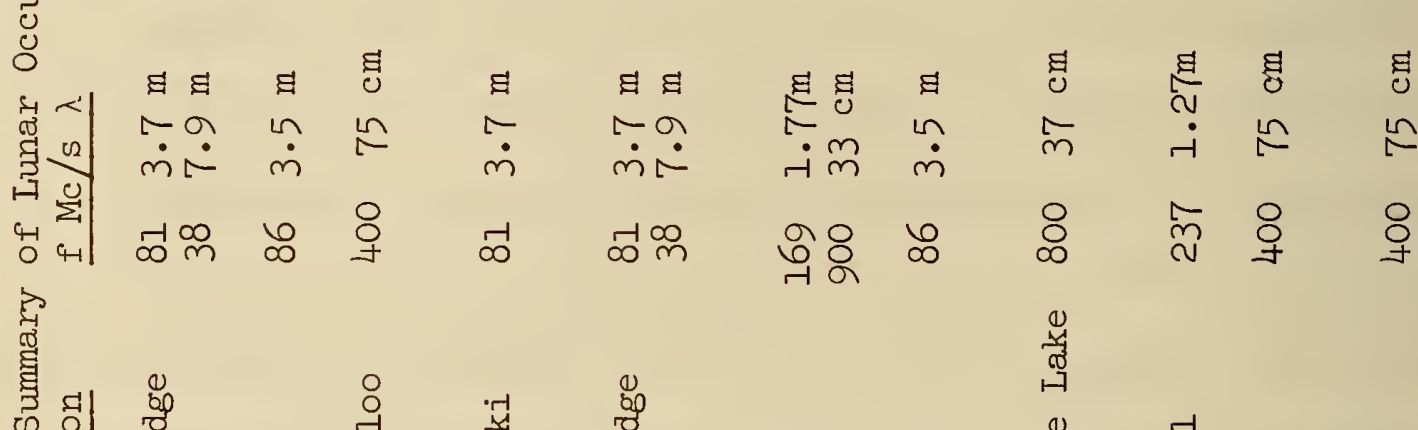

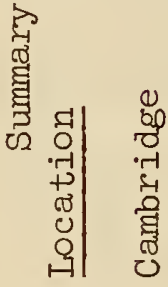

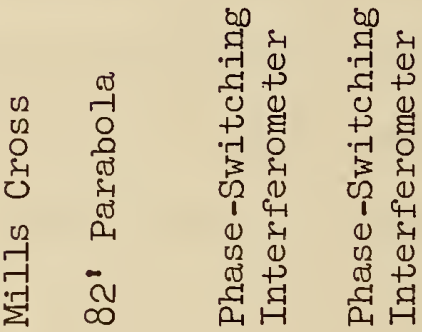

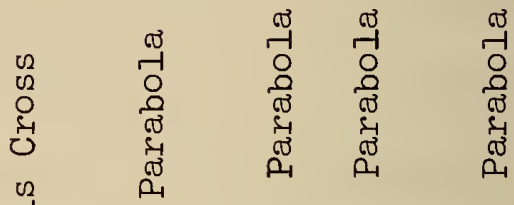

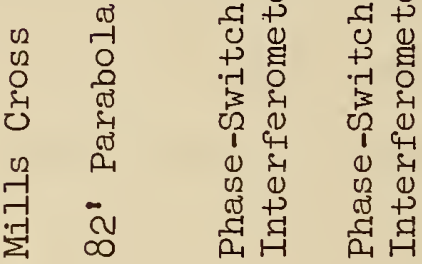

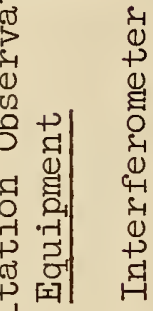

곡

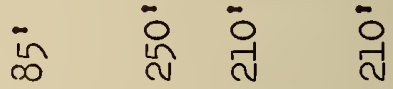


Table I summarizes some previous observations of lunar occultations which have been reported in the radio astronomy literature.

\section{OCCULTATIONS OF TAURUS A AND IC443 IN 1963-1964}

It was stated in Section I that the occultations of Taurus A and IC443 recur in a period of eight to nine years, with the next occultation season beginning late in 1963. The explanation for this cycle of recurrence is given simply by the relation of the orbit of the moon to the ecliptic. The angle of inclination of the lunar orbit to the ecliptic is $5^{\circ} 9^{\prime}$, so that the area of the sky traversed by the moon is a band $10^{\circ} 18^{\prime}$ wide centered on the ecliptic. Within this band the position and shape of the apparent lunar orbit continually changes, following a major cycle of about 19 years that is fixed by the period of the regression of nodes. The interval between occultations of sources within the lunar band is thus determined by the 19 year cycle and the particular ecliptic latitude of the source. Thus Taurus A and IC443, found within about $1^{\circ}$ of the ecliptic, are occulted about every half period, or every eight or nine years. The geometry of an occultation is, however, much different on alternate half-cycles. Figure 1 shows the path of the moon during the times of an occultation of IC443 in January 1956 and a half-cycle later in March 1964. The lunar band about the ecliptic is shown as a shaded area.

Figure 1 is constructed from geocentric coordinates taken from the American Ephemeris. Because of the significant horizontal parallax of the moon (about $1^{\circ}$ ) an exact calculation of a lunar occultation must be corrected for the geographic position of the observer, i.e., topocentric coordinates must be obtained. 


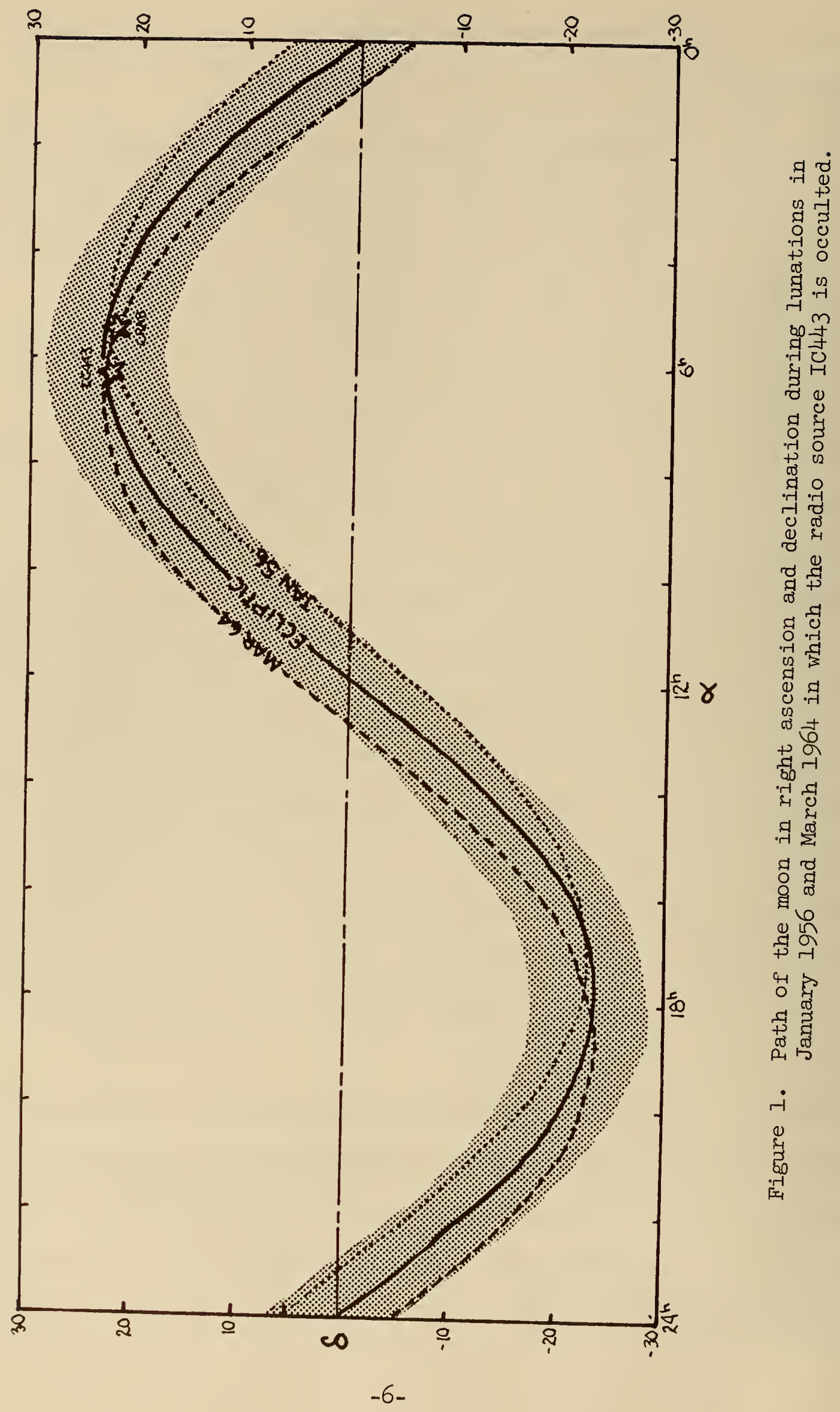


Table II lists the predicted occultations of Taurus A and IC443 during the 1963-64 season calculated for the geographic position $40^{\circ} .148$ $\mathrm{N}, 105^{\circ} .231 \mathrm{~W}$ (the midpoint of the T-22 interferometer at Table Mesa, north of Boulder). The source coordinates (epoch 1964) used in the calculations were the following:

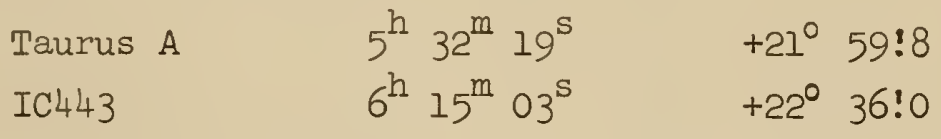

Taurus A (the Crab Nebula) is a source whose angular diameter is about $4^{\prime}$ of arc; thus any occultation by the moon (angular diameter $31^{\prime}$ ) is likely to be a total occultation. Occultations of this sort occur at Boulder on 13 May and $7 \mathrm{July}$ 1964. IC443, on the other hand, is a more extended source whose radio diameter (about $45^{\prime}$ ) is larger than that of the moon; thus an assortment of partial occultations is possible. The principal area of interest in IC443, at least at the longer wavelengths, is the north-following edge. Rishbeth [1956], in observing the partial occultation of the northern half of the nebula visible in Australia, noted that though only one tenth of the optical nebula was obscured, the $3.5 \mathrm{~m}$ radio radiation was reduced by over one fifth, and concluded that the optical bright arch on the north-following edge is the source of strongest radio emission. Observations of an occultation of the sourthern part of the nebula visible in England [Elsmore and Whitfield,1955] seemed to bear this out, for an obscuration of a large part of the southern half resulted in little change in radio flux. The occultations to occur in the 1963-64 season present a nice opportunity to check these earlier results, since a rather complete range of IC443 occultations is predicted. 


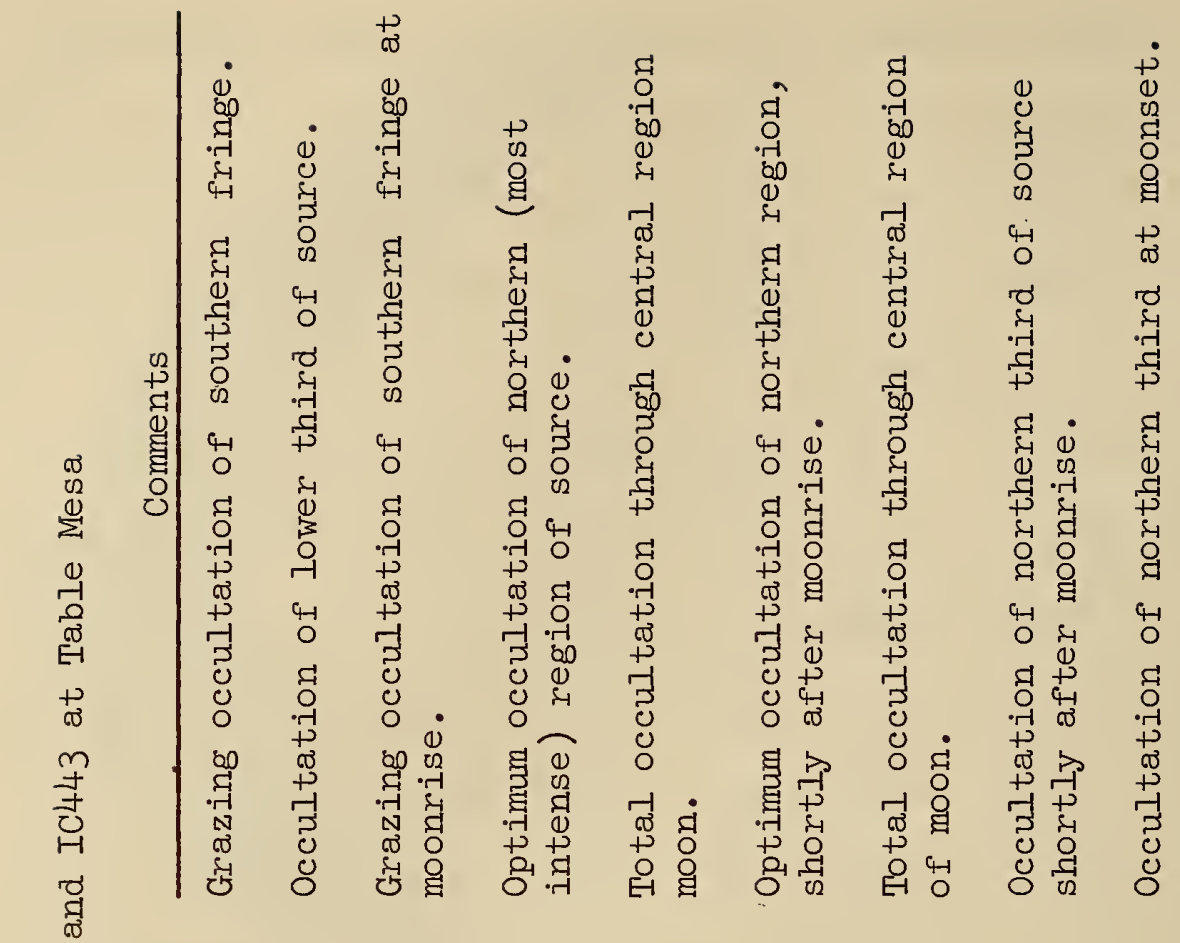

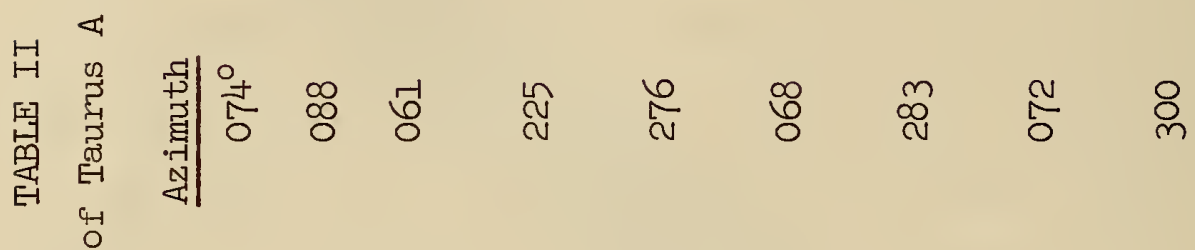

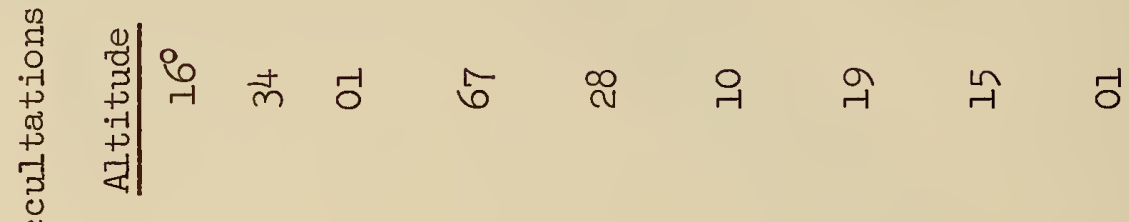

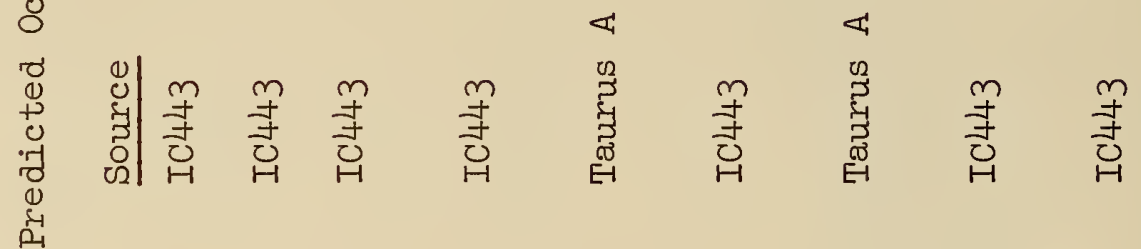

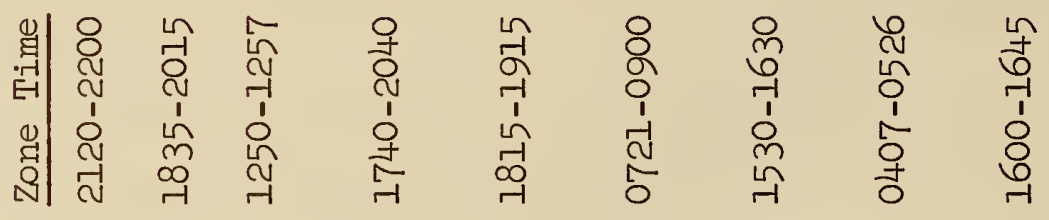

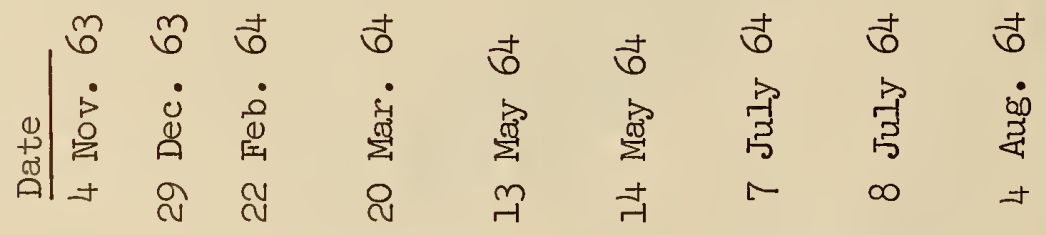


The predictions given above were calculated on the 7090 computer using a program, RSL007, written by R. S. Lawrence. For a given span of time at a given geographic location, the program computes (1) the geocentric altitude (a) and azimuth (A) of the moon, (2) the topocentric altitude of the moon ( $a^{\prime}$ ) using the formula

$$
a^{\prime}=a-\pi \cos a
$$

where $\pi$ = the interpolated equatorial horizontal parallax for the moon, and (3) the topocentric right ascension $\left[\alpha\left(a^{\prime}, A\right)\right]$ and declination [ $\left.\delta\left(a^{\prime}, A\right)\right]$ of the moon. Asphericity of the earth is neglected. As an aid to observation, the program also calculates the altitude and azimuth of a given grid of points that describe the position of an occulted source. The program is sufficiently general to predict the lunar occultation of any fixed source at any geographic location on the earth. One of the predictions was checked by hand using the rigorous formulae given in section $2 \mathrm{~F}$ of the Explanatory Supplement to the Ephemeris and was found to be accurate to within less than $0: 5$ of arc, indicating that the RSLOO7 predictions are satisfactory for predicting an occultation to within a few seconds of time. However, their use for data reduction purposes is not recommended. Completely precise predictions for individual occultations are probably best obtained from the Nautical Almanac Office; at least this has been the practice of previous observers [Rishbeth, 1956; Costain, Elsmore, and Whitfield, 1956]. Moreover, schedules of lunar occultations of a selected group of sources are furnished without charge on a routine basis by requesting this service from H. M. Nautical Almanac Office, Royal Greenwich Observatory. 


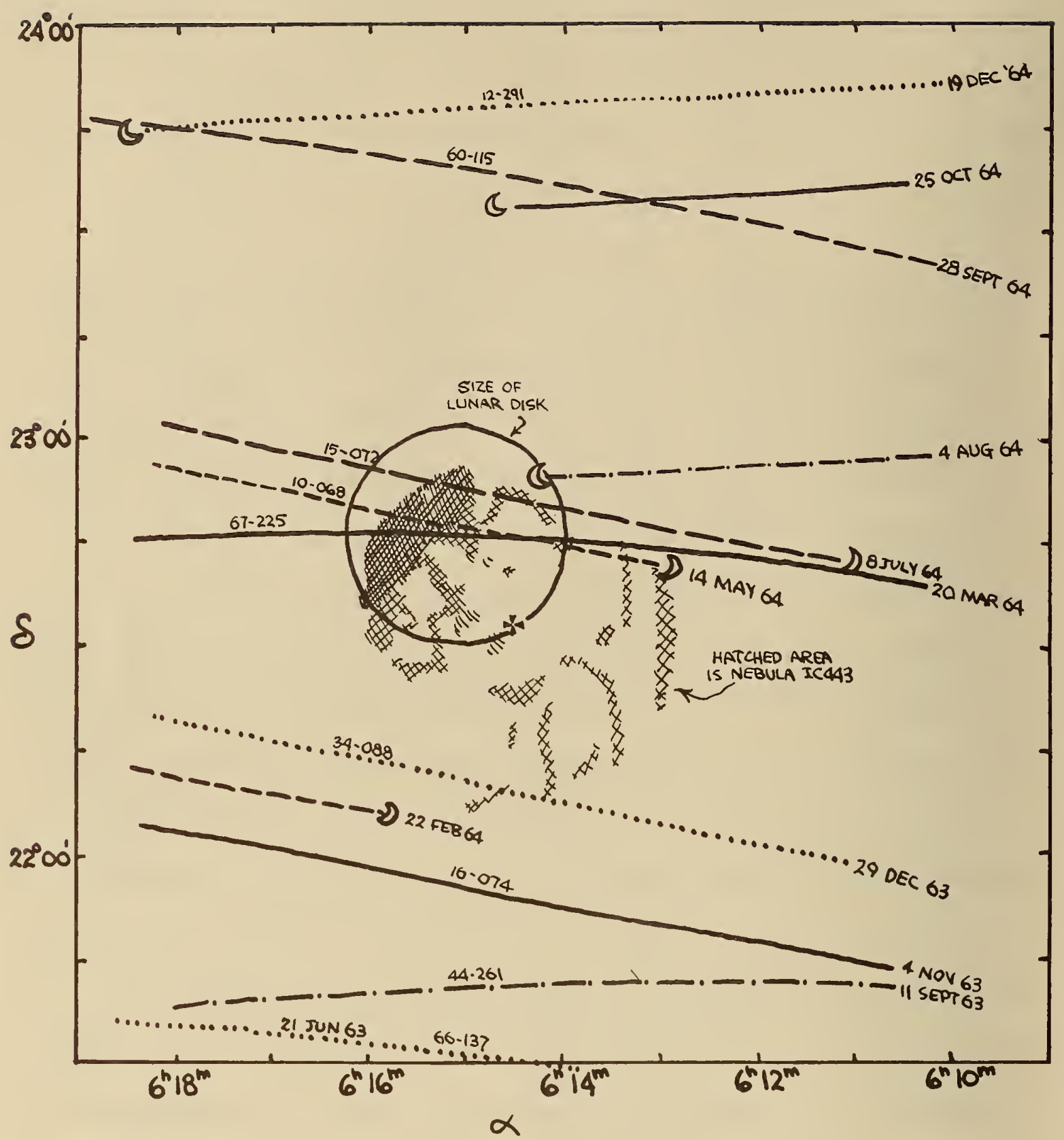

Figure 2. Path of the center of the moon at times of conjunction with the radio source IC443 as seen from Table Mesa from June 1963 through December 1964. The small lunar symbol denotes moonrise or moonset. Altitude and azimuth of the moon are given above each track for the time of closest approach to the radio source. Coordinates are topocentric right ascension and declination. 


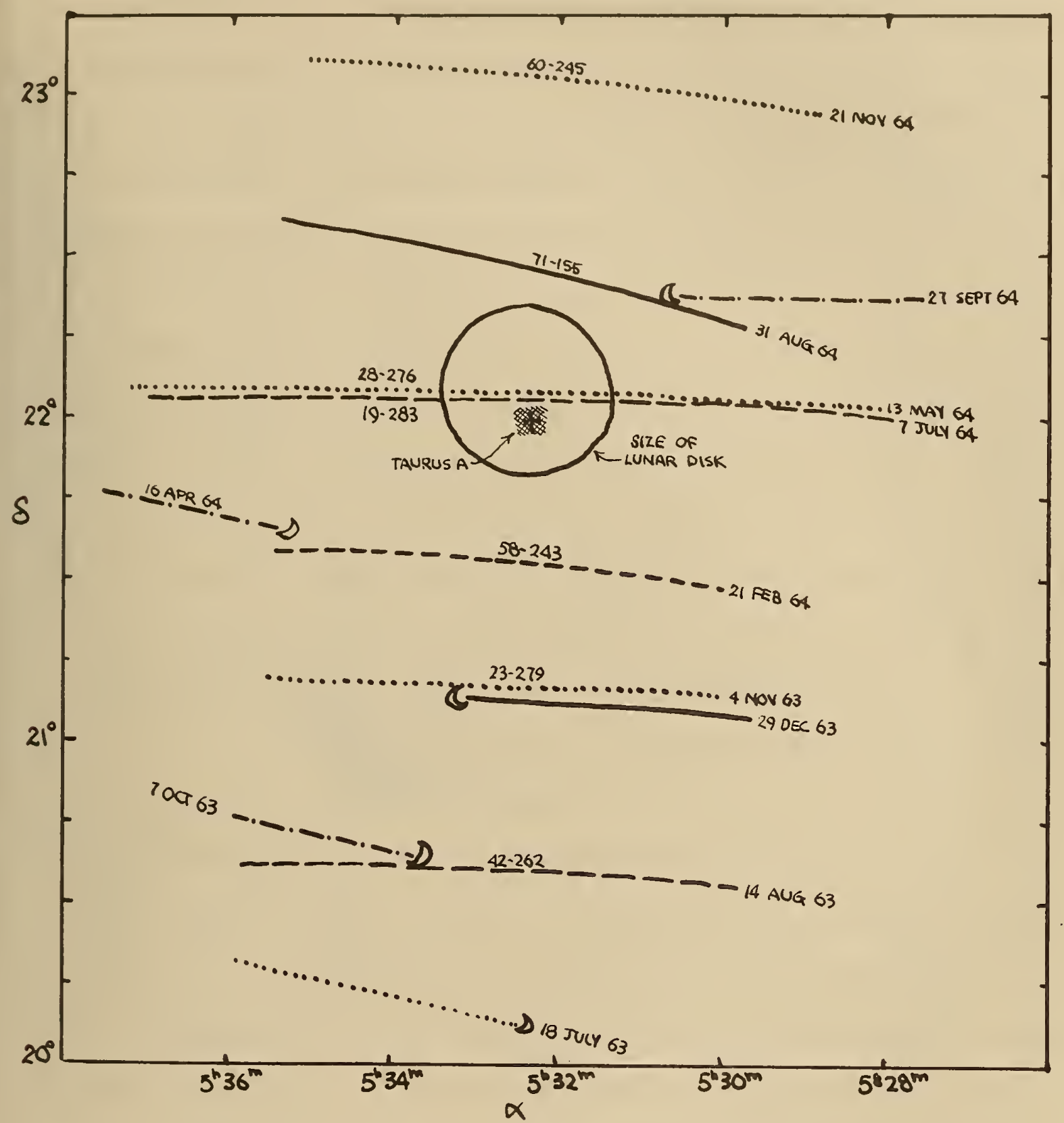

Figure 3. Path of the center of the moon at times of conjunction with the radio source Taums A as seen from Table Mesa from July 1963 through November 1964. The small lunar symbol denotes moonrise or moonset. Altitude and azimuth of the moon are given above each track for the time of closest approach to the radio source. Coordinates are topocentric right ascension and declination. 
Figures 2 and 3 show the positions of the center of the moon and the sources Taurus A and IC443 for the series of occultations and nearoccultations that are in the visible hemisphere at Boulder from June 1963 through December 1964; they indicate the general march of the moon through these two sky regions throughout this period. Coordinates are topocentric right ascension and declination for the geographic position of Table Mesa. Pairs of numbers (e.g. 67-225) given alongside the tracks indicate the approximate altitude and azimuth of the center of the moon at closest approach to the occulted source. A lunar symbol at either end of a track indicates moonrise and moonset. Figure 4 compares the geocentric and topocentric coordinates of the path of the center of the moon for the IC443 occultation of 20 March 1964 to demonstrate the effect of the coordinate conversion. The occultation on this date occurs at a rather high altitude (about $67^{\circ}$ ); the conversion effect would be more severe for events at lower altitudes.

\section{SUMMARY}

Lunar occultations of the radio sources Taurus A and IC443 will be observable at Boulder during late 1963 and early 1964 in step with a cycle of recurrence of about $8 \frac{1}{2}$ years. Taurus A will be occulted on two occasions, both at elevations below $30^{\circ}$ In the western sky. IC443, a more extended source, will undergo a series of very favorable partial occultations.

Figure 5 illustrates the onset and duration of the coming occultation season on a time scale that covers a period of about $1 \frac{1}{2}$ years. The ordinate is an importance scale, obtained rather subjectively by weighting together (a) the fraction of the source that is occulted by 


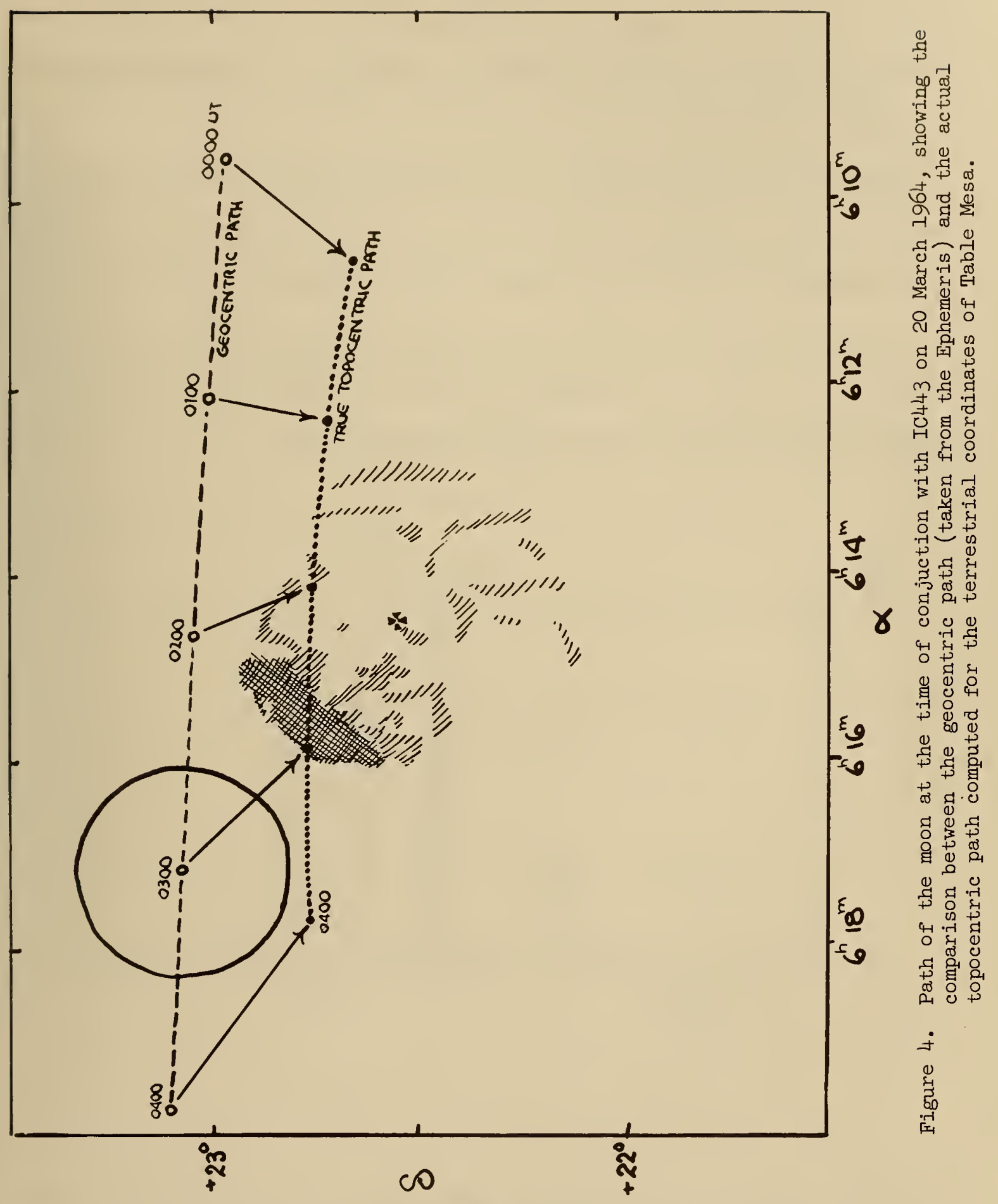


the moon, and (b) the observability of the particular occultation at Boulder. Thus, the optimum occultation of IC443 on 20 March 1964 is rated perfect at 1.0, while the partial occultation of the same source on 4 August 1964 that is interrupted by moonset is rated 0.1.

Observations of the Taurus A and IC443 occultations made during their last occurrence provided the first accurate determination of the angular extent of these two sources. The more favorable series of occultations coming up should be even more profitable, especially if observed on a variety of frequencies and at different polarizations. The opportunity will not come again in this decade.

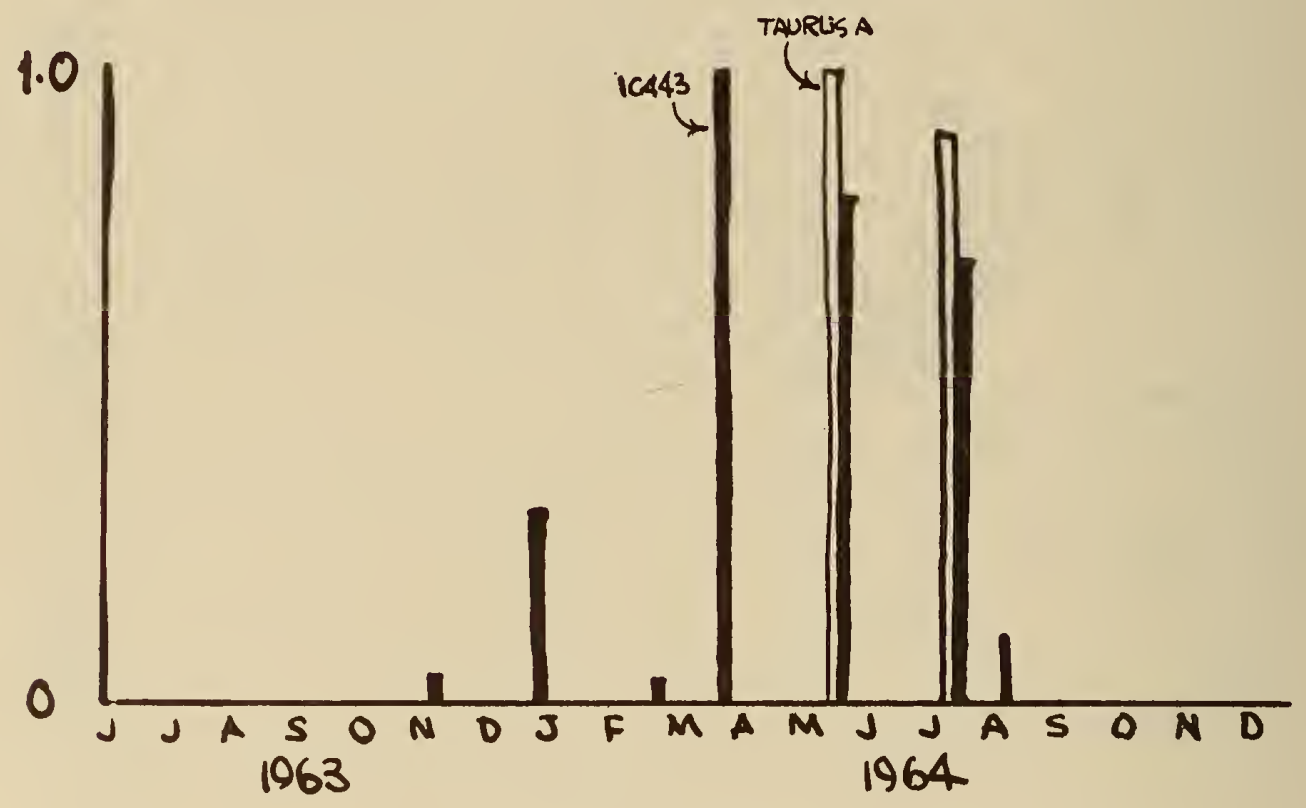

Figure 5. Graphical presentation of the data in Table 2, demonstrating the nature of the Occultation Season of 1963-1964. The ordinate is a scale of relative importance. 


\section{REFERENCES}

Bakulin, P. I., and I. S. Shklovski (1955) "Eclipses by the Moon of Two Discrete Sources of Radio Emission," Astron. Journal USSR, 32, 29-32; NRL Translation 526 by A. Pinge11, Washington D. C. 1955 .

Baldwin, J. E., and D. W. Dewhirst (1954) "Position and Identification of a Bright Extended Radio Source in Gemini," Nature, 173, 164-165.

Boischot, A., E. J. Blum, M. Ginat, and E. LeRoux (1956) "Observation d'une Eclipse de la Nebuleuse du Crabe," Comptes Rendus 242, 18491851 .

Bolton, J. G. (1963) "The Australian 210" Reflector and Its Research Program," Proc. IRE Australia, 24, 106-112.

Costain, C. H., B. Elsmore, and G. R. Whitfield (1956) "Radio Observations of a Lunar Occultation of the Crab Nebula." M.N.R.A.S. 116, 380-385.

Elsmore, B. (1957) "Radio Observations of the Lunar Atmosphere," Phil. $\mathrm{Mag}$. 2, 1040, No. 20.

Elsmore, B. (1958) "Radio Observations of the Lunar Atmosphere," Paris Symposium on Radio Astronomy, R. N. Bracewell, ed., Stanford University Press, Stanford, 47-48.

Elsmore, B., and G. R. Whitfield (1955) "Lunar Occultation of a Radio Star and the Derivation of an Upper Limit for the Density of the Lunar Atmosphere," Nature, 176, 457-458.

Hazard, C. (1961) "Lunar Occultation of a Radio Source," Nature 191, 58.

Link, F., and L. Neuzil (1954) "Occultation des Radiosources par la Lune en 1955-1957," Bull. Astr. Insts. Csl. 5, 112-115.

Rishbeth, H. (1956) "An Investigation of the Radio Source 06N2A in Gemini," Aust. J. Phys. 9, 494-504.

Rishbeth, H., and A. G. Little (1957) "A Lunar Occultation of the Radio Source Associated with Kepler's Supernova," Observatory, 77, 71-74.

Scheuer, P. A. G. (1962) "On the Use of Lunar Occultations for Investigating the Angular Structure of Radio Sources," Aust. J. Phys. 15, 333-343.

Seeger, C. I., and G. Westerhout (1957) "Observations of Two Occultations of the Crab Nebula by the Moon at $400 \mathrm{Mc} / \mathrm{s} . "$ B.A.N. 13, 312-316. 
Talen, J. (1963) (University of Michigan Radio Observatory) private communication.

Thominen, J., and M. Karras (1957) "A Lunar Occultation of the Crab Nebula at Wavelength 3.7 Meters," Suomalainen Tiedeakatemia, Series A, VI, Physica, 6. 


\section{THE NATIONAL BLREAU OF STANDARDS}

Nees pt of activities of the Niturmal Bureau of Standards at its major laboratories in Washington, D.C., and 3.5 r. Colorad", is suzgestcd in tle following listing of the divisions and sections engaged in technical work. is or m ral, each section rarries out specialized research, development, and engineering in the field indicated by it: th. A brief description of the activities, and of the resultant publications, appears on the inside of the The $t$ sever.

WISHILION, D. C.

Electricity. Resistance and Reactance. Electrochemistry. Electrical Instruments. Magnetic Measurements. Dele trics. High Voltage. Absolute Electrical Mleasurements.

Metrolog. Photometry and Colorimetry. Refractometry. Photographic Research. Length. Engineering Metrology. 11 ss and lolume.

Heat. T perature Physics. Heat Measurements. Cryogenic Physics. Equation of State. Statistical Physics. Radiation Phrsics. X-ray. Radioactivity. Radiation Theory. High Energy Radiation. Radiological Equipment. A-iknir Instrumentation. Neutron Physics.

Analycical and Inorganic Chemistry. Pure Substances. Spectrochemistry. Solution Chemistry. Standard Referin e Vaterials. Applied Analytical Research. Crystal Chemistry.

Mechanics. Sound. Pressure and Vacuum. Fluid Mechanics. Engineering Mechanics. Rheology. Combustion $\mathrm{x}$-trols.

Polymers. Macromolecules: Synthesis and Structure. Polymer Chemistry. Polymer Physics. Polymer Characifrization. Polvmer Evaluation and Testing. Applied Polymer Standards and Research. Dental Research.

Metallurgs. Engineering Metallurgy. Metal Reactions. Metal Physics. Electrolysis and Metal Deposition. Inorganic Solids. Engineering Ceramics. Glass. Solid State Chemistry. Crystal Growth. Physical Properties. Crvs allography.

Building Research. Structural Engineering. Fire Research. Mechanical Systems. Organic Building Materials. Codes and Safety Standards. Heat Transfer. Inorganic Building Materials. Metallic Building Materials.

Applied Vathematics. Numerical Analysis. Computation. Statistical Engineering. Mathematical Physics. Operatiols Research.

Data Processing Systems. Components and Techniques. Computer Technology. Measurements Automation. Eruneering Applications. Systems Analysis.

Itomic Physics. Spectroscopy. Infrared Spectroscopy. Far Ultraviolet Physics. Solid State Physics. Electron Physics. Atomic Physics. Plasma Spectroscopy.

instrumentation. Engineering Electronics. Electron Devices. Electronic Instrumentation. Mechanical Instruments. Basic Instrumentation.

Physical Chemistry. Thermochemistry. Surface Chemistry. Organic Chemistry. Molecular Spectroscopy. Elemeitary Processes. Mass Spectrometry. Photochemistry and Radiation Chemistry.

Office of heights and Measures.

BOLLDEH, COLO.

\section{CRYOGENIC ENGINEERING LABORATORY}

Cry g nic Processes. Cryogenic Properties of Solids. Cryogenic Technical Services. Properties of Cryogenic Fluids.

\section{CENTRAL RADIO PROPAGATION LABORATORY}

Ionosphere Research and Propagation. Low Frequency and Very Low Frequency Research. Ionosphere Research. Prediction Services. Sun-Earth Relationships. Field Engineering. Radio Warning Services. Vertical Sourditigs Research.

Troposphere and Space Telecommunications. Data Reduction Instrumentation. Radio Noise. Tropospheric 1. surements. Tropospheric Analysis. Spectrum Utilization Research. Radio-Meteorology. Lower Atmosphere Phys cs.

Radio Systems. Applied Electromagnetic Theory. High Frequency and Very High Frequency Research. Frequency Utilization. Modulation Research. Antenna Research. Radiodetermination.

Upper Atmosphere and Space Physics. Upper Atmosphere and Plasma Physics. High Latitude lonosphere $\mathrm{Ph}$ sics. Ionosphere and Exosphere Scatter. Airglow and Aurora. Ionospheric Radio Astronomy.

\section{RADIO STANDARDS LABORATORY}

Radio Standards Physics. Frequency and Time Disseminations. Radio and Microwave Materials. Atomic Fro quency and Time-lnterval Standards. Radio Plasma. Microwave Physics.

Radio Standards Engineering. High Frequency Electrical Standards. High Frequency Calibration Services. High Frequency Impedance Standards. Microwave Calibration Services. Microwave Circuit Standards. Low Frequency Calibration Services.

Joint Institute for Laboratory Astrophysics-NBS Group (Univ. of Colo.). 
NBS 